\title{
Preconceptional and prenatal exposure to diurnal temperature variation increases the risk of childhood pneumonia
}

\author{
Xiangrong Zheng ${ }^{1}$, Jian Kuang ${ }^{1}$, Chan Lu², Qihong Deng ${ }^{2,3,4}$, Haiyu Wu ${ }^{5}$, Rachael Gakii Murithi²,
} McSherry Brownel Johnson ${ }^{2}$, Wang Peng ${ }^{1}$ and Maolan $\mathrm{Wu}^{1}$

\begin{abstract}
Background: Pneumonia is the leading cause of death and hospitalization among young children worldwide, but its risk factors remain unclear.

Objective: To evaluate the effect of maternal exposure to diurnal temperature variation (DTV) during preconceptional and prenatal periods on childhood pneumonia.

Methods: A retrospective cohort study by case-control design was conducted for pneumonia $(N=699)$ and normal $(N=811)$ children under age of 14 who were enrolled in XiangYa Hospital, Changsha, China from May 2017 to April 2019. Demographic data including gender, age, birth season, gestational age, parity, mode of delivery, and parental atopy were collected from the electronic medical records in the hospital system. We obtained the data of daily DTV in Changsha during 2003-2019 from China Meteorological Administration. Maternal exposure to DTV during preconceptional and prenatal periods was respectively calculated by the average of daily DTV during one year and three months before conception and entire pregnancy as well as the three trimesters. The association between maternal exposure to outdoor DTV and childhood pneumonia was analyzed by multiple logic regression model.
\end{abstract}

Results: We found that childhood pneumonia was significantly associated with exposure to an increase in DTV during one year before conception and entire pregnancy, with ORs $(95 \% \mathrm{Cl})=2.53(1.56-4.10)$ and 1.85 (1.24-2.76). We further identified a significant risk of pneumonia of DTV exposure during the first and second trimester of pregnancy. Sensitivity analysis showed that boys were more susceptible to the effect of prenatal exposure to outdoor DTV during pregnancy particularly in the first two trimesters compared to girls.

Conclusions: Preconceptional and prenatal exposure to DTV plays an important role in development of childhood pneumonia, especially during the first and second trimesters of pregnancy.

Keywords: Diurnal temperature variation, Preconceptional, Pregnancy, Trimester, Childhood pneumonia

\footnotetext{
* Correspondence: chanlu@csu.edu.cn

${ }^{2}$ XiangYa School of Public Health, Central South University, 410078

Changsha, Hunan, China

Full list of author information is available at the end of the article
}

(c) The Author(s). 2021 Open Access This article is licensed under a Creative Commons Attribution 4.0 International License, which permits use, sharing, adaptation, distribution and reproduction in any medium or format, as long as you give appropriate credit to the original author(s) and the source, provide a link to the Creative Commons licence, and indicate if changes were made. The images or other third party material in this article are included in the article's Creative Commons licence, unless indicated otherwise in a credit line to the material. If material is not included in the article's Creative Commons licence and your intended use is not permitted by statutory regulation or exceeds the permitted use, you will need to obtain permission directly from the copyright holder. To view a copy of this licence, visit http://creativecommons.org/licenses/by/4.0/ The Creative Commons Public Domain Dedication waiver (http://creativecommons.org/publicdomain/zero/1.0/) applies to the data made available in this article, unless otherwise stated in a credit line to the data. 


\section{Background}

Pneumonia is the leading cause of death and hospitalization among children under age of 5 worldwide [1, 2]. Although pneumonia treatment has been improved significantly during past decades, the incidence of pneumonia in childhood remains high, especially in developing countries [3]. According to a recent epidemiological report, pneumonia has resulted in 808,694 deaths of children in 2017, which accounts for $15 \%$ of all deaths in children under 5 years [4]. Notably, China has witnessed a very high prevalence of childhood pneumonia over recent years [5]. Pneumonia not only influences the growth and development of children's lung, but also causes a heavy burden on family economy and public health [6]. Therefore, it is crucial to investigate the risk factors contributing to the frequent occurrence of childhood pneumonia, which would have a great implication for its effective reduction and early prevention.

Recently, there is increasing awareness that climatic variation significantly impacts childhood respiratory health. Pneumonia, as one of the most adverse infectious disease among children, has been suggested to be closely related to a continuous climate change $[7,8]$. Mounting evidences indicate that children suffer most from climate change due to their susceptibility for the extreme temperature and the dramatic weather change $[9,10]$. Some recent epidemiological studies from different regions have found an association between outdoor temperature and childhood pneumonia [11, 12]. Diurnal temperature variation (DTV), reflecting a degree in the daily temperature changes, has been found to be correlated with both mortality and morbidity of respiratory diseases [13-18]. Particularly, one of our recent cohort studies suggests that outdoor DTV is an important risk factor for pneumonia development in young children [19].

Early life exposure to harmful environmental factors could not only have an adverse effect on organ development and childhood growth, but also plays a critical role in the onset and progression of diseases in adulthood and has a long-term impact in the later life [20, 21]. Some studies have suggested that early-life exposure to temperature and DTV contributed to an increased risk of childhood respiratory diseases [19, 22-24]. Although a few studies have linked maternal exposure to trafficrelated air pollution (TRAP) during preconceptional period with increased risk of allergic diseases in preschool children $[25,26]$. Thus, maternal exposure to environmental factors before pregnancy could play an important role in the development of health outcomes during postnatal period. However, the effect of preconceptional exposure to outdoor DTV on respiratory outcomes, such as childhood pneumonia, have scarcely been investigated.

Due to the lack of studies on early life exposure to climatic change particularly before birth and children's health, we hypothesized that exposure to outdoor DTV during preconceptional and prenatal periods may be associated with later development of childhood pneumonia. To test this hypothesis and identify the critical timing window(s), we performed a large retrospective cohort study via case-control design in Changsha, China.

\section{Methods}

\section{Study population}

A retrospective cohort study by case-control design was conducted in the Department of Pediatrics, XiangYa hospital, Central South University in Changsha, China from May 2017 to April 2019. We recruited 699 children under 14 years old who were diagnosed with pneumonia and set them as the case group, and 811 healthy children who registered for physical examination as the control group. Children were excluded if they had abnormal congenital development in the airway and lung parenchyma, chronic lung disease, obstruction in the airway or compression outside the tube, congenital heart disease, tuberculosis, heart, liver and kidney diseases, or a known diagnosis of immunodeficiency.

The case group consisted of children with a diagnosis of pneumonia made in accordance with the following WHO diagnosis criteria [27]. Cough or difficult breathing plus at least one of the following signs: (1) fast breathing (rate $>60$ breaths per minute if aged $<2$ months, $>50$ breaths per minute if aged 2-11 months, and $>40$ breaths per minute if aged 12-59 months); or (2) lower chest wall indrawing. In addition, either crackles or pleural rub may be present on chest auscultation. The control group included healthy children who didn't have a history of pneumonia diagnosis based on WHO criteria at the time of recruitment.

\section{Demographic data}

We collected the demographic data from the electronic medical records system in the hospital, including children's gender, age, birth season, gestational weeks, parity, mode of delivery, and parental atopy. Parental atopy was defined by the presence of a history of any allergic diseases among child's mother and/or father.

\section{Exposure assessment \\ Exposure timing windows}

Exposure timing-windows included preconceptional and prenatal periods in this study. The preconceptional exposure involved in two timing windows: one year before conception and three months before conception. The prenatal period was defined from the first day of the mother's last menstrual period to the delivery day. The prenatal exposure was further divided into three trimesters: the first trimester (from the 1st to 12th weeks of gestation), second trimester (the 13 th to 27 th weeks of 
gestation), and third trimesters (from the 28th gestational week to the birthday of the child).

\section{Personal exposure to diurnal temperature variation (DTV)}

We obtained the data of daily temperature (including the mean, maximum, and minimum temperatures) at ten different monitoring stations in Changsha during 2003-2019 from China Meteorological Administration: Kaifu district, Yuhua district, Furong district, Liuyang county, Mapoling, Ningxiang county, Tianxin district, Wangcheng district, Yuelu district, and Changsha county. The diurnal temperature variation (DTV) was calculated as the difference between the daily maximum and minimum temperature. Children's exposure was estimated by DTV at the station where their residence was located. Then, the individual exposure to outdoor DTV for each child was calculated as follows: (1) Preconceptional exposure to DTV was calculated as the average of daily DTV during one year and three months before conception, (2) Prenatal exposure to DTV was calculated by the average of daily DTV during the period from the mother's last menstrual period to the delivery day; (3) The exposure to DTV in the first, send, and third trimester was respectively calculated as the average of daily DTV during the periods of 1st - 12th gestational weeks, 13th -27 th gestational weeks, and from the 28th gestational week till the date of birth.

\section{Exposure to outdoor air pollution}

Exposure to outdoor air pollution was considered as an important confounding variable for pneumonia risk in this study. We obtained daily $24 \mathrm{~h}$-averaged concentrations of three main air pollutants, including nitrogen dioxide $\left(\mathrm{NO}_{2}\right)$, sulfur dioxide $\left(\mathrm{SO}_{2}\right)$, and particulate matter $\leq 10 \mu \mathrm{m}$ in diameter $\left(\mathrm{PM}_{10}\right)$, from 7 municipal air quality monitoring stations in Changsha from 2003 to 2019. Individual exposure to ambient air pollution during different timing windows was estimated by the inverse distance weighted (IDW) method described in our previous work [28].

\section{Statistical analysis}

Statistical analyses were performed by SPSS software (version 23.0, SPSS Inc., Chicago, USA). The relationship between exposure to outdoor DTV during preconceptional and prenatal periods and childhood pneumonia was assessed by using multiple logistic regression model, with adjusting potential variables in Table 1 and the three air pollutants $\left(\mathrm{NO}_{2}, \mathrm{SO}_{2}\right.$, and $\left.\mathrm{PM}_{10}\right)$. The associations in regression analysis was calculated by odds ratio (OR) of $95 \%$ confidence interval $(95 \% \mathrm{CI})$. In our study, OR $(95 \% \mathrm{CI})$ was estimated by per $1{ }^{\circ} \mathrm{C}$ increase in exposure to outdoor DTV. The data were drawn into a
Table 1 Demographic information of covariates among children with (case) and without (control) doctor-diagnosed pneumonia $(n=1,510)$

\begin{tabular}{|c|c|c|c|c|c|c|c|}
\hline & \multicolumn{2}{|l|}{ Total } & \multicolumn{2}{|c|}{ Case } & \multicolumn{2}{|c|}{ Control } & \multirow[b]{2}{*}{$P$-value } \\
\hline & $\mathrm{N}$ & (\%) & $\mathrm{N}$ & $(\%)$ & $\mathrm{N}$ & $(\%)$ & \\
\hline Total & 1,510 & $(100.0)$ & 699 & $(46.3)$ & 811 & (53.7) & - \\
\hline Sex & & & & & & & $<0.001$ \\
\hline Boys & 865 & $(57.3)$ & 436 & (50.4) & 429 & (49.6) & \\
\hline Girls & 645 & $(42.7)$ & 263 & (40.8) & 382 & $(59.2)$ & \\
\hline Age (years) & & & & & & & $<0.001$ \\
\hline$<1$ & 402 & $(26.6)$ & 334 & (83.1) & 68 & (16.9) & \\
\hline$=1$ & 323 & $(21.4)$ & 130 & $(40.2)$ & 193 & (59.8) & \\
\hline$>1$ & 785 & $(52.0)$ & 235 & (29.9) & 550 & (70.1) & \\
\hline Birth season & & & & & & & 0.048 \\
\hline Spring & 342 & $(22.6)$ & 138 & $(40.4)$ & 204 & (59.6) & \\
\hline Summer & 392 & $(26.0)$ & 184 & $(46.9)$ & 208 & (53.1) & \\
\hline Autumn & 422 & $(27.9)$ & 197 & $(46.7)$ & 225 & (53.3) & \\
\hline Winter & 354 & $(23.4)$ & 180 & (50.8) & 174 & $(49.2)$ & \\
\hline Parity & & & & & & & 0.046 \\
\hline $1 s t$ & 1,025 & $(67.9)$ & 454 & $(44.3)$ & 571 & (55.7) & \\
\hline $2 n d-5$ th & 478 & $(31.7)$ & 238 & (49.8) & 240 & $(50.2)$ & \\
\hline \multicolumn{2}{|c|}{ Gestational age (weeks) } & & & & & & $<0.001$ \\
\hline$<37$ & 92 & $(6.1)$ & 62 & (67.4) & 30 & (32.6) & \\
\hline$\geq 37$ & 1,418 & $(93.9)$ & 637 & $(44.9)$ & 781 & (55.1) & \\
\hline Mode of delivery & & & & & & & $<0.001$ \\
\hline Natural labour & 863 & $(57.2)$ & 360 & $(41.7)$ & 503 & $(58.3)$ & \\
\hline Caesarean birth & 641 & $(42.5)$ & 333 & $(52.0)$ & 308 & $(48.0)$ & \\
\hline Parental atopy & & & & & & & $<0.001$ \\
\hline No & 1,432 & $(94.8)$ & 646 & $(45.1)$ & 786 & $(54.9)$ & \\
\hline Yes & 78 & $(5.2)$ & 53 & $(67.9)$ & 25 & (32.1) & \\
\hline
\end{tabular}

Sum of the number is not 1,510 due to missing data. The $p$-values $<0.05$ were in bold

figure by Origin software (version: OriginPro 2018 C). $P$ value $\leq 0.05$ was considered as statistically significant.

\section{Results}

Data on the demographics and prevalence of pneumonia stratified by the covariates are given in Table 1 . The total material $(N=1,510)$ included 699 children with pneumonia and 811 healthy children without pneumonia or other respiratory diseases. We conducted one-way analysis of variance to examine the association between childhood pneumonia and the considered potential covariates. We found that boys, younger children $(<1$ year old), children with gestational age $<37$ weeks (preterm birth), delivery mode of caesarean, and parental atopy had a significantly higher prevalence of pneumonia than girls, older children, children with gestational age $\geq 37$ weeks, natural delivery mode and without parental 
Table 2 Descriptive statistics for outdoor temperature and DTV during different time windows attributed to the children $(n=1,510)$

\begin{tabular}{|c|c|c|c|c|c|c|c|}
\hline & \multicolumn{2}{|l|}{ Total } & \multicolumn{2}{|l|}{ Case } & \multicolumn{2}{|c|}{ Control } & \multirow[t]{2}{*}{$P$-value } \\
\hline & Mean & $\overline{(S D)}$ & Mean & $\overline{(S D)}$ & Mean & $\overline{(S D)}$ & \\
\hline \multicolumn{8}{|l|}{ Preconceptional } \\
\hline 1 year before conception & 7.2 & $(0.5)$ & 7.3 & $(0.4)$ & 7.2 & $(0.5)$ & $<0.001$ \\
\hline 3 months before conception & 7.2 & $(0.8)$ & 7.3 & $(0.7)$ & 7.1 & $(0.8)$ & $<0.001$ \\
\hline \multicolumn{8}{|l|}{ Prenatal } \\
\hline 1st trimester & 7.2 & $(0.8)$ & 7.3 & $(0.7)$ & 7.0 & $(0.8)$ & $<0.001$ \\
\hline 2nd trimester & 7.1 & $(0.7)$ & 7.3 & $(0.7)$ & 6.9 & $(0.7)$ & $<0.001$ \\
\hline 3rd trimester & 7.1 & $(0.7)$ & 7.3 & $(0.7)$ & 6.9 & $(0.7)$ & $<0.001$ \\
\hline Entire pregnancy & 7.1 & $(0.5)$ & 7.3 & $(0.5)$ & 7.0 & $(0.5)$ & $<0.001$ \\
\hline
\end{tabular}

DTV $\left({ }^{\circ} \mathrm{C}\right)=$ Tmax - Tmin. The $p$-values $<0.05$ were in bold

atopy, and the $\mathrm{p}$-values were statistically significant $(p<$ 0.05). Furthermore, we observed that the prevalence of pneumonia was significantly higher in children born in winter compared to the other seasons.

Data on ambient DTV during different periods between the case and control group were given in Table 2. The average of individual exposure to DTV during one year before conception and three months before conception were both $7.3^{\circ} \mathrm{C}$ in the case group and 7.2 and $7.1^{\circ} \mathrm{C}$ in the control group, with a statistically significant difference ( $p$ values $<0.001)$. The mean DTV exposure during entire pregnancy was significantly larger in children with pneumonia $\left(7.3^{\circ} \mathrm{C}\right)$ than that in healthy children $\left(7.0^{\circ} \mathrm{C}\right)$, $p$ value $<0.001$. Moreover, we observed that exposure to DTV during all the three trimesters of pregnancy were significantly larger in children with pneumonia than healthy children $(p<0.001)$

We further evaluated the relationship between DTV exposure during preconceptional and prenatal periods and childhood pneumonia by using multiple logistic regression model, with an adjustment of the potential variables (Table 3). We found that maternal exposure to
DTV was significantly associated with childhood pneumonia, particularly for a long-term exposure, with the adjusted OR $(95 \% \mathrm{CI})$ of $2.53(1.56-4.10)$ for per $1{ }^{\circ} \mathrm{C}$ increase in DTV exposure during one year before conception. We also detected significant associations of childhood pneumonia with prenatal exposure to outdoor DTV during entire pregnancy especially in the first and second trimester, with adjusted ORs $(95 \% \mathrm{CI})=1.85$ $(1.24-2.76), \quad 1.63(1.32-2.00)$ and $1.43 \quad(1.12-1.81)$ respectively.

Figure 1 showed pneumonia risk of prenatal DTV exposure stratified by children's gender. We observed that the odds of pneumonia due to DTV exposure during the second trimester and entire pregnancy were significant only in boys but not in girls. Furthermore, the association between DTV exposure in the first trimester was greater among boys than that among girls.

\section{Discussion}

In this retrospective cohort study, we are the first to find a significant association between maternal exposure to outdoor DTV during one year before conception and

Table 3 Odds ratio $(95 \% \mathrm{Cl})$ of childhood pneumonia for exposure to outdoor DTV during different timing-windows $(n=1,510)$

\begin{tabular}{|c|c|c|c|}
\hline & Crude OR & Adjusted model I & Adjusted model II $^{\mathrm{b}}$ \\
\hline \multicolumn{4}{|l|}{ Preconceptional } \\
\hline 3 months before conception & $1.40(1.22,1.61)^{* * *}$ & $1.98(1.67,2.34)^{* * *}$ & $1.15(0.91,1.46)$ \\
\hline 1 year before conception & $1.86(1.48,2.32)^{* * *}$ & $10.21(7.08,14.71)^{* * *}$ & $2.53(1.56,4.10)^{* * *}$ \\
\hline \multicolumn{4}{|l|}{ Prenatal } \\
\hline 1st trimester & $1.72(1.50,1.97)^{* * *}$ & $2.30(1.94,2.72)^{* * *}$ & $1.63(1.32,2.00)^{* * *}$ \\
\hline 2nd trimester & $1.99(1.71,2.33)^{* * *}$ & $2.55(2.12,3.07)^{* * *}$ & $1.43(1.12,1.81)^{* *}$ \\
\hline 3rd trimester & $1.88(1.62,2.18)^{* * *}$ & $2.29(1.91,2.73)^{* * *}$ & $1.20(0.96,1.51)$ \\
\hline Entire pregnancy & $4.45(3.52,5.6)^{* * *}$ & $8.36(6.21,11.27)^{* * *}$ & $1.85(1.24,2.76)^{* *}$ \\
\hline
\end{tabular}

OR $(95 \% \mathrm{Cl})$ was estimated by $1{ }^{\circ} \mathrm{C}$ increase in outdoor DTV during each time window.

${ }^{\text {a }}$ Model I was adjusted for the covariates in Table 1.

${ }^{\mathrm{b}}$ Model II was further adjusted for outdoor air pollution exposure during each time window based on model I.

* $p \leq 0.05$.

** $p \leq 0.01$.

*** $p \leq 0.001$ 


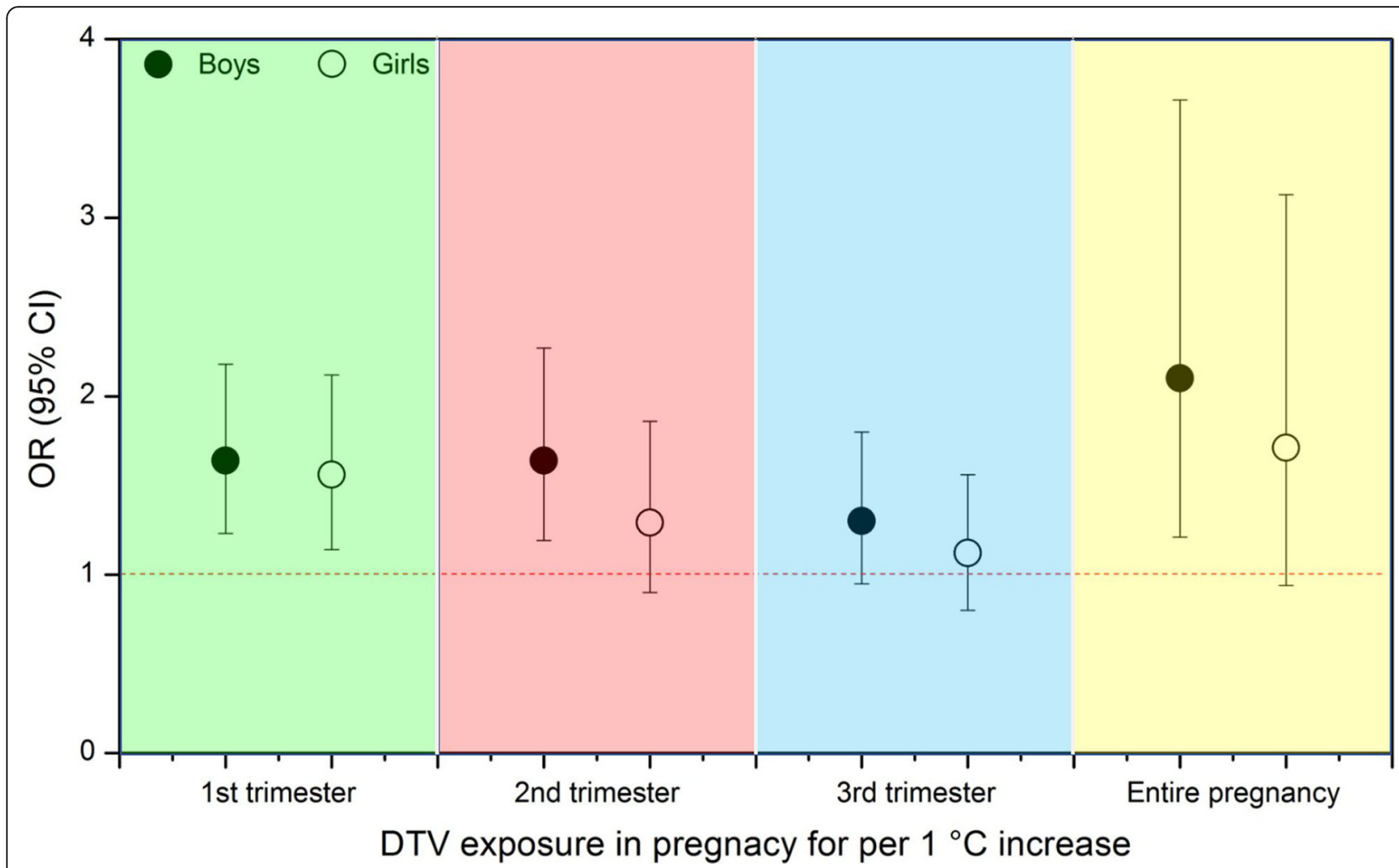

Fig. 1 Odds ratio $(95 \% \mathrm{Cl})$ of childhood pneumonia for exposure to diurnal temperature variation (DTV) stratified by gender during pregnancy $(n=1,510)$. ORs was adjusted for all covariates in Table 1 and outdoor air pollutants $\left(\mathrm{PM}_{10}, \mathrm{SO}_{2}\right.$ and $\left.\mathrm{NO}_{2}\right)$

childhood pneumonia. We also observed that prenatal exposure to DTV during pregnancy, especially in the first and second trimesters, was significantly associated with an increased risk of childhood pneumonia, supporting the hypothesis of "fetal origin of diseases". Our sensitivity analysis indicated that boys were more vulnerable to the pneumonia risk of prenatal exposure to DTV than girls.

Previous studies have suggested that DTV exposure may play a significant role in the increased risk of respiratory diseases [29-31], including asthma, allergy and respiratory tract infection (RTI) among young children [32-34]. However, the evidence in the association between DTV and childhood pneumonia is still controversial $[19,35]$. Our study newly indicates that early-life exposure to a large DTV could be a risk factor contributing to the development of childhood pneumonia.

As far as we know, the present study is the first to find that increased maternal DTV exposure during the year prior conception has an adverse effect on the later development of pneumonia in children. Previous studies mainly associated preconceptional exposure to air pollution with childhood health problems. A cohort study in China suggested that preconceptional exposure to traffic- and industry-related air pollutants was significantly related withchildhood asthma [26]. $\mathrm{NO}_{2}$ exposure during three months before conception was reported to be linked with eczema risk in children [25]. Another recent retrospective study in US proved a significant relationship between preconceptional exposure to $\mathrm{NO}_{\mathrm{X}}$ and $\mathrm{SO}_{2}$ and an increased risk of gestational diabetes mellitus (GDM) [36]. Furthermore, a multi-site study found that preconceptional exposure to $\mathrm{PM}_{10}, \mathrm{SO}_{2}$ and $\mathrm{CO}$ was linked with increased risk of oral cleft [37]. Therefore, it is reasonable to believe that preconceptional exposure to DTV significantly increased the risk of childhood pneumonia, which may indicate a hypothesis of "pre-fetal origin of childhood infection".

Professor David Barker, a British epidemiologist, first proposed the theory of the development origins of health and diseases (DOHaD): early life (prenatal and early postnatal periods) exposure to environmental factors affects the plasticity of development, leading to the development and/or deterioration of various complex diseases in adulthood. Therefore, early life was considered as a critical timing window of environmental exposure which is related to human health. In this study, we observed that prenatal exposure to a large DTV was a significant risk factor for pneumonia development in children, which is in line with a recent cohort study from China [19]. We further identified that the first and second trimester of pregnancy was the critical time windows for 
DTV exposure contributing to the development of childhood pneumonia, which was scarcely observed in previous literatures. Exposure to a large DTV in the first trimester of pregnancy was found to be associated with frequent common colds among preschool children in China [22]. One of our recent studies have indicated a significant association between exposure to industrial air pollutant $\mathrm{SO}_{2}$ during the first trimester of pregnancy and increased risk of childhood ear infection [38]. The mechanisms underlying the association between childhood pneumonia and prenatal exposure to DTV during the first and second trimesters of pregnancy remain unclear. It was suggested that lung development starts at about the 4th gestational week, nad the airway branching morphogenesis occurs in the first two trimesters of gestation [39]. Hence, long-term exposure to environmental factors in utero may lead to an improper development of lung at various degree, which could affect postnatal development of lung function and induce a risk of respiratory diseases later in life. However, the pathogenic mechanisms underlying childhood pneumonia risk of intrauterine exposure to DTV warrants further investigations.

A recent study [13] and one of our recent work [19] indicated that boys were more susceptible to the effect of prenatal exposure to DTV in pregnancy on pneumonia risk compared to girls. According to the reports from Global Burden of Disease Study 2017 (GBD 2017), the prevalence of respiratory tract infections in males was significantly higher than females [40]. Some evidence suggested that the gender difference of environmental susceptibility was mainly related to immune response [41]. In general, females are more responsive to pathogenic stimuli and vaccines than males, and thus females are more resistant to infectious diseases [42]. Whereas, the mechanisms in the sex-related susceptibility in the effect of DTV exposure on childhood infections including pneumonia remain unclear, which is profound to further study.

Our study had several limitations for the data collection and analysis. Firstly, the data of personal exposure to outdoor air temperature was only obtained from one meteorological station, this may result in exposure misclassification. In spite of the fact that environmental temperature changes in different areas of one city (Changsha) are small, this may lead to exposure classification errors, and using temperature exposure with high spatial resolution to capture the temperature difference in the areas of inner-city may perform a better exposure assessment [43]. Secondly, indoor air temperature was not considered in the present study. However, as people especially pregnant women spend most of their time indoors, the long-term exposure to indoor air temperature may impact the health condition among pregnant mothers and young childhood. Thirdly, other meteorological parameters including relative humidity, wind speed, and precipitation were not included in our study.These climatic factors may affect air temperature or temperature change, and thus their potential influence should not be ignored. At last, we didn't consider the possibility of the change of residence of the mother during the preconception or prenatal period, however, most of them would like to stay at home and always like to work near their residence because it may waste a lot time if they live far from their working place due to rush hour in Chinese cities.

\section{Conclusions}

This retrospective cohort study via case-control design reveals that preconceptional (one year before conception) and prenatal exposure to DTV was significantly associated with childhood pneumonia. We identified the first two trimesters of pregnancy as the critical time windows. Our results have a clinical significance in assessing the onset and development of pneumonia. Our study also provide a novel strategy for effective reduction and early prevention of childhood pneumonia, i.e., reducing outdoor activities among women preparing for pregnancy when the temperature changes sharply, and avoiding extra exposure to a large variation in daily temperature during pregnancy especially in the first and second trimesters.

\section{Abbreviations}

DTV: Diurnal temperature variation; IDW: Inverse distance weighted

\section{Acknowledgements \\ We sincerely appreciate the children and their families as well as the kindergartens for their great support and enthusiastic participation. We also thank to all the teachers and students who participated and contributed to our work.}

\section{Authors' contributions}

XZ conducted the study, analyzed the data, and drafted the initial manuscript. JK collected and analyzed the data, and drafted part of the manuscript. CL conceptualized, designed and performed the study, supervised the data analysis, and drafted and revised the manuscript. QD guided and revised the manuscript as well as critically reviewed the manuscript for important intellectual content. HW, RGM, MBJ, WP, MW conducted the study, analyzed the data, and reviewed the revised manuscript. All authors have read and approved the manuscript.

\section{Funding}

This study was supported by the National Natural Science Foundation of China (No. 81873851, 42007391, 81861138005), the Natural science foundation of Hunan Province (NO.2018JJ6141), and Health and Family Planning Commission of Hunan Province (No. B20180881). the key special focus project of China Hunan Provincial Science and Technology Department (No. 2020SK3025, 2020SK3045). The funders had no role in study design, data collection and analysis, decision for publish, or preparation of the manuscript.

\section{Availability of data and materials}

The data sets used and/or analyzed during the current present study are available from the corresponding author on reasonable request. 


\section{Declarations}

\section{Ethics approval and consent to participate}

This study was approved by the academic ethics committee of XiangYa Hospital (201904107). A written consent was obtained from a parent or guardian for all individual participants included in the study.

\section{Consent for publication}

Not applicable.

\section{Competing interests}

The authors declare that they have no competing interesting. Furthermore, Chan Lu, as a member of the editorial board (Associate Editor) of this journal, declares to ensure transparency and no conflict of interest was reported.

\section{Author details}

'Department of Pediatrics, XiangYa Hospital, Central South University, Changsha, Hunan, China. ${ }^{2}$ XiangYa School of Public Health, Central South University, 410078 Changsha, Hunan, China. ${ }^{3}$ School of Energy Science and Engineering, Central South University, Changsha, Hunan, China. ${ }^{4}$ School of Public Health, Zhengzhou University, Zhengzhou, Henan, China. ${ }^{5}$ XiangYa School of Medicine, Central South University, Changsha, Hunan, China.

Received: 3 July 2020 Accepted: 2 April 2021

Published online: 21 April 2021

\section{References}

1. Walker CF, Rudan I, Liu L, Nair H, Theodoratou E, Bhutta ZA, et al. Global burden of childhood pneumonia and diarrhoea. Lancet. 2013;381(9875): 1405-16.

2. Liu L, Oza S, Hogan D, Perin J, Rudan I, Lawn JE, et al. Global, regional, and national causes of child mortality in 2000-13, with projections to inform post-2015 priorities: an updated systematic analysis. Lancet. 2015;385(9966): 430-40.

3. Rudan I, Boschi-Pinto C, Biloglav Z, Mulholland K, Campbell H. Epidemiology and etiology of childhood pneumonia. Bulletin of the world health organization. 2008;86:408-16.

4. World Health Organization. pneumonia. 2019. https://www.who.int/newsroom/fact-sheets/detail/pneumonia. Accessed 2 August 2019.

5. Jiang W, Lu C, Miao Y, Xiang Y, Chen L, Deng Q. Outdoor particulate air pollution and indoor renovation associated with childhood pneumonia in China. Atmos Environ. 2018;174:76-81.

6. McMichael AJ. Globalization, climate change, and human health. N Engl J Med. 2013:368(14):1335-43

7. Kim J, Kim JH, Cheong HK, Kim H, Honda Y, Ha M, et al. Effect of Climate Factors on the Childhood Pneumonia in Papua New Guinea: A Time-Series Analysis. Int J Environ Res Public Health. 2016;13(2):213.

8. Paynter S, Ware R, Weinstein P, Williams G, Sly PD. Childhood pneumonia: a neglected, climate-sensitive disease? Lancet. 2010;376(9755):1804-5.

9. McKie R. Children will suffer most as climate change increases in coming decades, say scientists. BMJ. 2013;347:f5799.

10. Xu Z, Etzel RA, Su H, Huang C, Guo Y, Tong S. Impact of ambient temperature on children's health: a systematic review. Environ Res. 2012; 117:120-31.

11. Lam HCY, Chan EYY, Goggins WB. Short-term Association Between Meteorological Factors and Childhood Pneumonia Hospitalization in Hong Kong: A Time-series Study. Epidemiology. 2019;30(Suppl 1):107-14.

12. Xu Z, Liu Y, Ma Z, Li S, Hu W, Tong S. Impact of temperature on childhood pneumonia estimated from satellite remote sensing. Environ Res. 2014;132: 334-41.

13. Ding Z, Guo P, Xie F, Chu H, Li K, Pu J, et al. Impact of diurnal temperature range on mortality in a high plateau area in southwest China: A time series analysis. Sci Total Environ. 2015;526:358-65.

14. Zhou X, Zhao A, Meng X, Chen R, Kuang X, Duan X, et al. Acute effects of diurnal temperature range on mortality in 8 Chinese cities. Sci Total Environ. 2014:493:92-7.

15. Yang J, Liu HZ, Ou CQ, Lin GZ, Zhou Q, Shen GC, et al. Global climate change: impact of diurnal temperature range on mortality in Guangzhou, China. Environ Pollut. 2013;175:131-6.

16. Chen C, ZHOU W, GUI Y, Kan H. Diurnal temperature range as a novel risk factor for sudden infant death. Biomed Environ Sci. 2011;24(5):518-22.
17. Sun S, Laden F, Hart JE, Qiu H, Wang Y, Wong CM, et al. Seasonal temperature variability and emergency hospital admissions for respiratory diseases: a population-based cohort study. Thorax. 2018;73(10):951-8.

18. Cheng J, Xu Z, Zhu R, Wang X, Jin L, Song J, Su H. Impact of diurnal temperature range on human health: a systematic review. Int J Biometeorol. 2014;58(9):2011-24.

19. Zeng J, Lu C, Deng Q. Prenatal exposure to diurnal temperature variation and early childhood pneumonia. J Therm Biol. 2017;65:105-12.

20. Heindel JJ, Vandenberg LN. Developmental origins of health and disease: a paradigm for understanding disease cause and prevention. Curr Opin Pediatr. 2015;27(2):248-53.

21. Barker DJ, C O. Infant mortality, childhood nutrition, and ischaemic heart disease in England and Wales. Lancet. 1986;327:1077-81.

22. Lu C, Miao Y, Zeng J, Jiang W, Shen YM, Deng Q. Prenatal exposure to ambient temperature variation increases the risk of common cold in children. Ecotoxicol Environ Saf. 2018;154:221-7.

23. Miao Y, Shen YM, Lu C, Zeng J, Deng Q. Maternal exposure to ambient air temperature during pregnancy and early childhood pneumonia. J Therm Biol. 2017;69:288-93.

24. Gluckman PD, Hanson MA, Cooper C, Thornburg KL. Effect of in utero and early-life conditions on adult health and disease. N Engl J Med. 2008;359(1): 61-73.

25. Lu C, Deng L, Ou C, Yuan H, Chen X, Deng Q. Preconceptional and perinatal exposure to traffic-related air pollution and eczema in preschool children. J Dermatol Sci. 2017:85(2):85-95.

26. Deng Q, Lu C, Ou C, Chen L, Yuan H. Preconceptional, prenatal and postnatal exposure to outdoor and indoor environmental factors on allergic diseases/symptoms in preschool children. Chemosphere. 2016; 152:459-67.

27. World Health Organization. Pocket book of hospital care for children: guidelines for the management of common illnesses with limited resurces. 2nd ed. Geneva: World Health Organization; 2013.

28. Deng Q, Lu C, Norback D, Bornehag CG, Zhang Y, Liu W, Yuan H, Sundell J. Early life exposure to ambient air pollution and childhood asthma in China. Environ Res. 2015;143(Pt A):83-92.

29. Wang MZ, Zheng S, He SL, Li B, Teng HJ, Wang SG, et al. The association between diurnal temperature range and emergency room admissions for cardiovascular, respiratory, digestive and genitourinary disease among the elderly: a time series study. Sci Total Environ. 2013;456-457:370-5.

30. Lim YH, Hong YC, Kim H. Effects of diurnal temperature range on cardiovascular and respiratory hospital admissions in Korea. Sci Total Environ. 2012:417:55-60.

31. Liang WM, Liu WP, Kuo HW. Diurnal temperature range and emergency room admissions for chronic obstructive pulmonary disease in Taiwan. Int J Biometeorol. 2009;53(1):17-23.

32. Li T, Yang Z, Wang M. Diurnal temperature range related to respiratory tract infection in childhood. Pediatr Infect Dis J. 2014:33(12):1309-10.

33. Ge WZ, Xu F, Zhao ZH, Zhao JZ, Kan HD. Association between diurnal temperature range and respiratory tract infections. Biomed Environ Sci. 2013;26(3):222-5.

34. Xu Z, Huang C, Su H, Turner LR, Qiao Z, Tong S. Diurnal temperature range and childhood asthma: a time-series study. Environ Health. 2013;12(1):12.

35. Xu Z, Hu W, Tong S. Temperature variability and childhood pneumonia: an ecological study. Environ Health. 2014;13(1):51

36. Robledo CA, Mendola P, Yeung E, Männistö T, Sundaram R, Liu D, et al. Preconception and early pregnancy air pollution exposures and risk of gestational diabetes mellitus. Environ Res. 2015;137:316-22.

37. Zhu Y, Zhang C, Liu D, Grantz KL, Wallace M, Mendola P. Maternal ambient air pollution exposure preconception and during early gestation and offspring congenital orofacial defects. Environ Res. 2015;140:714-20.

38. Deng Q, Lu C, Li Y, Chen L, He Y, Sundell J, et al. Association between prenatal exposure to industrial air pollution and onset of early childhood ear infection in China. Atmos Environ. 2017;157:18-26.

39. Schittny JC. Development of the lung. Cell Tissue Res. 2017;367(3):427-44.

40. Spencer L, James D, Abate KH, Abate, Solomon M, Abay C, Abbafati N, Abbasi H, Abbastabar, et al. Global, regional, and national incidence, prevalence, and years lived with disability for 354 diseases and injuries for 195 countries and territories, 1990-2017: a systematic analysis for the Global Burden of Disease Study 2017. Lancet. 2018;392:1789-858.

41. Muenchhoff M, Goulder PJJTJoid. Sex differences in pediatric infectious diseases. JID. 2014;209(suppl_3):120-6. 
42. Edwards M, Dai R, Ahmed SA. Our Environment Shapes Us: The Importance of Environment and Sex Differences in Regulation of Autoantibody Production. Front Immunol. 2018;9:478.

43. Zhong Q, Lu C, Zhang W, Zheng X, Deng Q. Preterm birth and ambient temperature: strong association during night-time and warm seasons. J Therm Biol. 2018;78:381-90.

\section{Publisher's Note}

Springer Nature remains neutral with regard to jurisdictional claims in published maps and institutional affiliations.

Ready to submit your research? Choose BMC and benefit from:

- fast, convenient online submission

- thorough peer review by experienced researchers in your field

- rapid publication on acceptance

- support for research data, including large and complex data types

- gold Open Access which fosters wider collaboration and increased citations

- maximum visibility for your research: over $100 \mathrm{M}$ website views per year

At BMC, research is always in progress.

Learn more biomedcentral.com/submissions 